\title{
Experimental Research on The Effect of Silica Fume on Tensile Basic Creep of Early-age Concrete
}

\author{
Wang Xinjie*, Zhu Pinghua and Xia Qun
}

School of Environmental and Safety Engineering, Changzhou University, Changzhou, Jiangsu, 213164, China

\begin{abstract}
The tensile creep behavior is extremely important in crack prediction and stress analysis of concrete. The main objective is investigating the effects of the silica fume on the tensile basic creep of early-aged concrete. The effect of silica fume on tensile creep was studied using lever-type tensile creep tester. Silica fume amount by weight of total cementing material was $0 \%, 5 \%, 10 \%$ and $15 \%$. Results show that concrete exhibits larger tensile basic creep strain if loaded at early age. The development characteristic of tensile basic creep of concrete with different silica fume content is that development rate is relatively fast after loading $12 \mathrm{~h}$, and slowes down gradually after loading $12 \mathrm{~h}$. The early age tensile basic creep of concrete increases with the increasing of the content of silica fume.
\end{abstract}

Keywords: Silica fume, specific creep, tensile basic creep.

\section{INTRODUCTION}

Silica fume is a substance resulting from a chemical reaction taking place between high purity quartz and coke in the process of smelting ferro-silicon. It can be collected from high temperature waste gas in the flues by using dust collecting device. If silica fume is discharged into the air along with the exhaust gas of electric-arc furnace, serious dust pollution will be caused. It contained amorphous $\mathrm{SiO}_{2}$ more than $90 \%$. The silica fume has less average particle size and larger surface area and the chemical property of silica fume is rather unstable. Hydrated calcium silicate with gel property will be generated after it takes reaction with $\mathrm{Ca}(\mathrm{OH})_{2}$ which is the hydration product of cement. Silica fume is a kind of high active pozzolanic materials $[1,2]$.

By the addition of silica fume into concrete can not only solve the problem of reuse of industrial waste, but also can improve the workability of concrete mixture, reduce its segregation and bleeding, improve the interface structure between the hardened cement paste and aggregate, reinforce the bonding strength between hardened cement paste and aggregate, improve the mechanical properties of concrete. Silica fume was often used in preparation of high strength, high performance concrete. However, some problems such as volume instability, prone to cracking of high strength and high performance concrete were raised at early age, which can reduce the durability of the concrete [3].

The shrinkage deformation of concrete is one of the most direct reasons caused cracks of concrete at early-age, while tensile creep produced by shrinkage stress of restrained member is able to relieve tensile stress due to shrinkage, the maximum can reach above $50 \%$. The significant effect of tensile creep of early-age concrete plays an important the role on reducing tensile stress and delaying cracking [4]. Studies about tensile creep of early-age concrete in current literatures are rather less, not to mention studies on the influence of silica fume on early-age concrete. Therefore, this paper will research the effect of silica fume on tensile creep of early-age concrete.

\section{EXPERIMENTAL}

\subsection{Materials}

Cement: P.O 42.5 ordinary Portland cement produced by Jiangsu Pangu Cement Group co.ltd.

Coarse aggregate: The maximum size of coarse aggregate is $25 \mathrm{~mm}$. The minimum size of coarse aggregate is $5 \mathrm{~mm}$. Silt content is $0.2 \%$. Apparent density is $2700 \mathrm{~kg} / \mathrm{m}^{3}$.

Fine aggregate: Ordinary river sand, and fineness modulus of fine aggregate is 3.0 , mud content is $1.2 \%$, apparent density is $2650 \mathrm{~kg} / \mathrm{m}^{3}$.

Additive: Polycarboxylic acid high-performance water reducing agent JM-PCA, produced by Jiangsu Bote New Material Co., Ltd.

\section{Water: Tap water}

Silica fume: Surface area of silica fume is $20 \mathrm{~m}^{2} / \mathrm{kg}$. The diameter of silica fume particle is about $0.1-0.2 \mu \mathrm{m}$. The content of $\mathrm{SiO}_{2}$ reaches up to $95 \%$ above.

\subsection{Mix Proportion of Test}

At present, the maximum content of silica fume is $15 \%$ by the weight of cementing material in concrete. In order to study the influence of the content of silica fume on tensile creep of concrete, silica fume $(0 \%, 5 \%, 10 \%$ and $15 \%$ by weight of cement) was added to concrete partially replace cement. In the process of study the influence of silica fume content on tensile creep of concrete, to avoid other influencing factors on tensile basic creep of concrete, method of 
Table 1. Composition of concrete mixes.

\begin{tabular}{|c|c|c|c|c|c|c|c|}
\hline \multirow{2}{*}{ Test No. } & \multicolumn{6}{|c|}{ Composition of concrete mixes $\left(\mathrm{kg} / \mathrm{m}^{3)}\right.$} & \multirow[b]{2}{*}{ w/c ratio } \\
\hline & Water & Cement & River sand & Gravel & Silica fume & $\begin{array}{c}\text { Water reducing } \\
\text { agent }\end{array}$ & \\
\hline $\mathrm{RC}$ & 195 & 488 & 601 & 1116 & 0 & 1.952 & 0.40 \\
\hline A & 195 & 439.2 & 601 & 1116 & 24.4 & 2.440 & 0.40 \\
\hline $\mathrm{C}$ & 195 & 341.6 & 601 & 1116 & 73.2 & 3.904 & 0.40 \\
\hline
\end{tabular}

fixing content of aggregate, sand ratio, total volume of binding material and water-binder ratio of concrete was adopted. During the process of mixing concrete, cement was replaced with equivalent weight of silica fume. Table $\mathbf{1}$ shows the compositions of the concrete mixes. The water-binder ratio $(\mathrm{w} / \mathrm{b})$ of 0.40 was selected. Mixture slump was around $120 \mathrm{~mm}$ by using a high-range water-reducing admixture.

\subsection{Fabrication and Test Method of Tensile Creep Specimens}

The tensile creep experiment was conducted on a levertype tensile creep device by which axial tensile stress is applied on the concrete specimens. The tensile testing machine device is shown in Fig. (1). Specific theory refers to literature [5]. The size of the tensile creep specimen was $100 \mathrm{~mm} \times 100 \mathrm{~mm} \times 515 \mathrm{~mm}$. Pull rods are embedded at both ends of the specimens for applying tensile force. Embedded pull rods and deformation measuring stents are fixed on moulds after release agent is painted on the interior surfaces of the test moulds. The distance between the deformation measuring stents is $200 \mathrm{~mm}$. Then the specimens are covered with polyethylene films and placed in curing room after vibrated and compacted. And the specimens were sealed immediately when moulds was removed before the age of $24 \mathrm{~h}$ so as to avoid the exchange of moisture with outside. Autogenous shrinkage was also occurred besides tensile basic creep whiles the concrete under external tensile force. Therefore, the autogenous shrinkage deformation value was necessary to be considered. Method of preparation of autogenous shrinkage specimens was same with tensile creep specimens. The specimens were sealed immediately after the moulds were removed. Deformation of autogenous shrinkage values was measured in the creep laboratory with the temperature was $20 \pm 2^{\circ} \mathrm{C}$.

The splitting tensile strength was tested on the pressure tester at the age of 3 days to determine the applied load on the specimens of concrete creep, and the stress is about 0.4 times of splitting tensile strength. Then, tensile creep specimens were installed on lever-tensile creep testing machine and displacement meters were fixed on deformation measuring stents. Tensile stress was applied on the creep specimens for 7 days. The readings of displacement meter were recorded before and after the loading were applied. Then the readings were recorded for each time after loading $1 \mathrm{~h}, 6 \mathrm{~h}$, $12 \mathrm{~h}$. From the time under loading of $24 \mathrm{~h}$, two times were observed everyday until test was completed after 7 days. Meanwhile, deformation of shrinkage-compensating test specimens was observed. Specimens size of splitting tensile strength is $150 \mathrm{~mm} \times 150 \mathrm{~mm} \times 150 \mathrm{~mm}$. The fabrication method, curing and testing of specimens of splitting tensile strength of concrete were performed in according with GBT 50081-2002(Standard for Test Method of Mechanical Properties on Ordinary Concrete) [6].

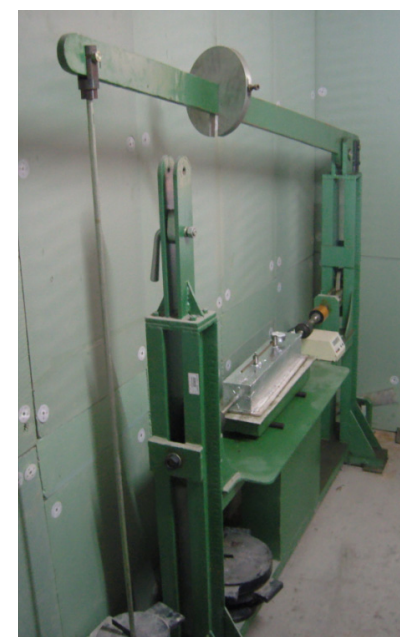

Fig. (1). Testing Device of Lever-type Tensile Creep.

\section{RESULTS}

\subsection{Influence of Silica on Splitting Tensile Strength}

The splitting tensile strength of concrete for different content of silica fume was studied at the age of 3 days. The result of splitting tensile strength of concrete with different displacement ratio is shown in Fig. (2).

It could be known from Fig. (2) that the splitting tensile strength increased with the increasing of the content of silica fume at the age of 3 days. By the addition of fume, the water segregation rate of concrete was reduced, which prevented moisture gathering below aggregate, contributed to the microscopic structure of interface transition area between cement paste and aggregate became similar with cement paste, enhanced density degree of interface transition area, effectively reduced thickness of interface transition area. At the same time, pores structure in cement paste was changed by pozzolanic reaction. The number of pore that the diameters more than $0.11 \mu \mathrm{m}$ reduced while the pore diameter less than $0.105 \mu \mathrm{m}$ increased. Pore diameter became smaller and $\mathrm{Ca}(\mathrm{OH})_{2}$ in cement paste reduced, crystal became thinning. 
In addition, fine silica fume particle would be filled in gap of cement particles which made paste become more dense [7]. Thus the strength of concrete was increased gradually with increasing of content of silica fume.

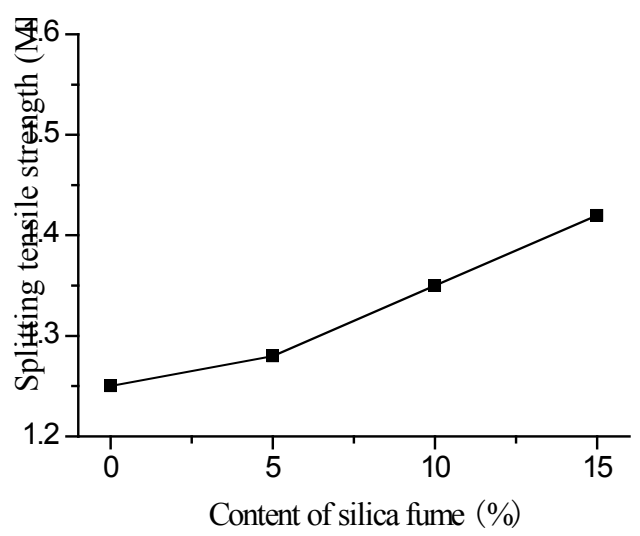

Fig. (2). Influence of Silica Fume on Splitting Tensile Strength of Concrete.

\subsection{Effect of Silica Fume on Elasticity Modulus of Con- crete}

Tension elasticity modulus of early-age concrete was obtained from elastic stage of tensile creep test. The effect of silica fume on tensile elasticity modulus of concrete is sketched in Fig. (3). As shown in Fig. (3), there might be some unknown reason happened during testing process which made elasticity modulus of mix B was less than that of mix A. But the total trend was that elasticity modulus of concrete was increased with increasing of the silica fume content. It was caused by silica fume which reduced the porosity of transition area between aggregate and harden cement paste. Total stiffness of silica fume concrete increased and early stage hydration speed of concrete was speeded up. Therefore, the tensile elasticity modulus of concrete at early age was increased with the increasing of silica fume content.

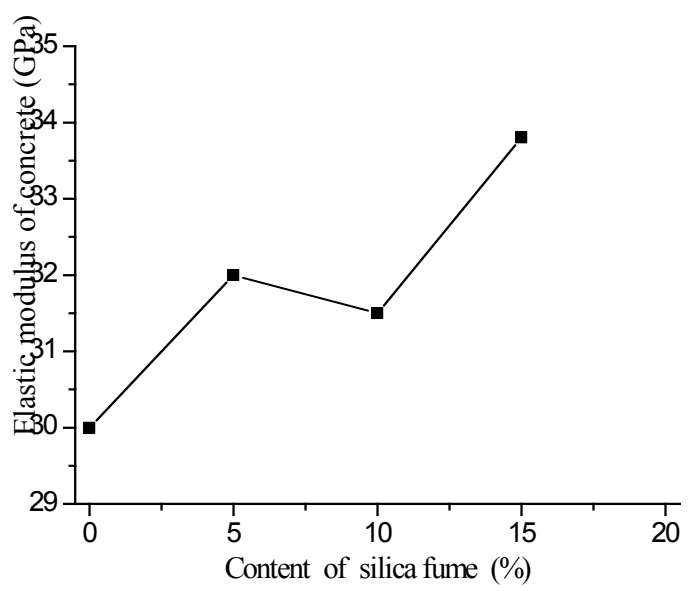

Fig. (3). Effect of Silica Fume on Elasticity Modulus of Concrete.

\subsection{Effect of Silica Fume on Autogenous Shrinkage of Concrete}

The deformation of shrinkage-compensating concrete includes autogenous shrinkage deformation and temperature deformation. Due to sectional dimension of concrete specimen is $100 \mathrm{~mm} \times 100 \mathrm{~mm}$, and the average temperature in the laboratory is $20 \pm 2^{\circ} \mathrm{C}$, it can be deemed that the measured deformation was autogenous shrinkage deformation of free shrinkage test specimens after 1 day under sealing condition. The effect silica fume on autogenous shrinkage of concrete is shown in Fig. (4). From the Fig. (4), it could be stated that the autogenous shrinkage of concrete increased with increasing of silica fume content. It was caused by filling function of silica fume which made the content of macrospores inside of cement paste decreased obviously, while the content of microspores increased. And the total porosity was not changed too much. In addition, the more content of silica fume, the above mentioned phenomenon became more obvious [8]. Therefore, ritical radius $r_{0}$ caused by self-drying would be decreased with increasing of content of silica fume, and meniscus pressure $\Delta p$ would be increased. Thus the autogenous shrinkage of concrete increased with the increasing of silica fume content.

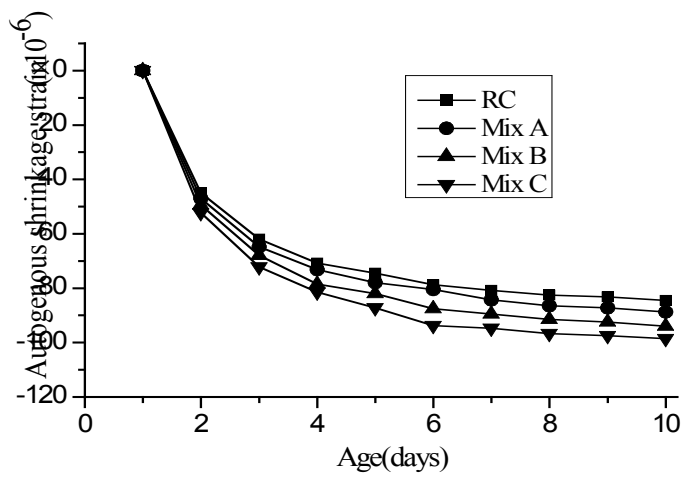

Fig. (4). Time-dependent Change in Autogenous Shrinkage.

\subsection{Effect of Silica Fume on Tensile Creep of Concrete}

At the age of 3 days, according to results of splitting tensile strength, the average stress applied on concrete specimens with reference concrete, mix $\mathrm{A}, \operatorname{mix} \mathrm{B}, \operatorname{mix} \mathrm{C}$ is $0.931 \mathrm{MPa}, 0.953 \mathrm{MPa}, 0.988 \mathrm{MPa}, 1.065 \mathrm{MPa}$, which equivalents to $39.0 \%, 38.6 \%, 37.9 \%, 38.7 \%$ and $37.3 \%$ of splitting tensile strength at the age of 3 days respectively.

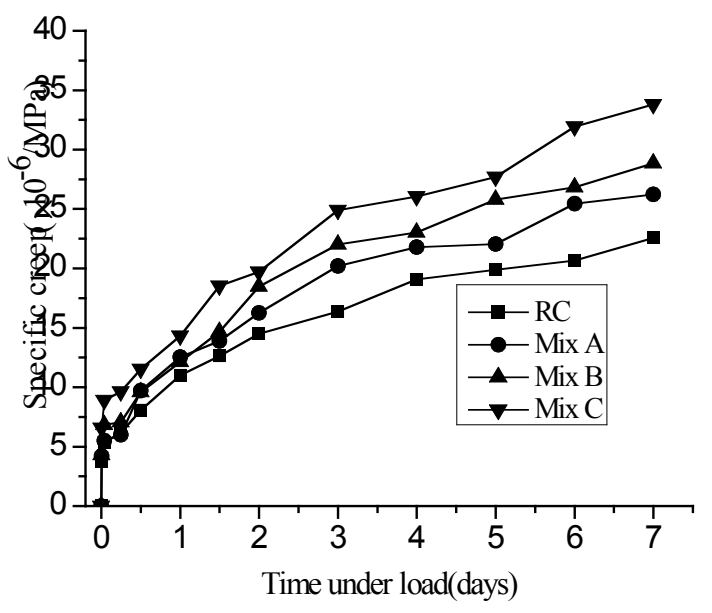

Fig. (5). Effect of Silica Fume on Specific Creep of Concrete. 
Fig. (5) shows the effects of silica fume on specific creep of concrete. It could be pointed from Fig. (5) that the development characteristic of tensile basic creep of concrete with different silica fume content was that development rate was relatively fast after loading $12 \mathrm{~h}$, and slowed down gradually after loading $12 \mathrm{~h}$. The specific creep of reference concrete, mix $\mathrm{A}-\mathrm{C}$ at the time under load of $12 \mathrm{~h}$ is $35.7 \%, 37.0 \%, 33.3 \%, 34.1 \%$ of the specific creep at the time under load of 7 days respectively. The basic law of development of specific creep was not changed by addition of silica fume. Besides, the specific creep of concrete was increased gradually with the increasing of silica fume content. The specific creep of concrete with mix $A-C$ is $1.16,1.28$ and 1.50 of reference concrete respectively. And it could be seen that the influence of silica fume on specific creep of concrete was obviously.

\section{ANALYSIS OF ACTION MECHANISM OF SILICA FUME ON TENSILE CREEP OF CONCRETE}

It could be considered that the creep of concrete was result of continuous development of initial micro-cracks inside of concrete in according to the micro-crack mechanism of creep of concrete, while these micro-cracks grew up gradually during process of pouring concrete and hardening. For tensile loading, when stress-strength ratio of external tensile exceeds 0.2 or less, there may appear micro-cracks propagation at initial imperfection place [9]. Elastic strain energy and new crack surface energy released by microcracks propagation, which would increase with extension of cracks. The micro-cracks will stop developing until necessary energy for new cracks propagation surpassed strain energy released by crack propagation, while because of the existing of absorbing water could lower the surface energy of concrete. When micro-cracks developed, surface energy of concrete would slow down as absorbing water enter into the new micro-crack continuously, and tensile creep of concrete would be developed gradually.

The effect of silica fume on tensile creep of concrete can be explained by micro-crack mechanism. After silica fume was mixed in concrete, due to the higher fineness of silica fume which could greatly lower bleeding performance of concrete, prevent water gathering under aggregate, and make interface transitional area between aggregate and harden cement paste similar to structure of cement paste, thus the density degree of interface transitional area was increased, while the thickness of interface transitional area was decreased effectively. However, after mixed with silica fume, the content of macropore and coarse pore in cement paste was decreased obviously. And content of fine pores whose pore diameter was less than $30 \AA$ was increased, while the change of total porosity was small. The meniscus pressure formula of pores as follow:

$\Delta P=\frac{2 \sigma \cos \theta}{r_{0}}$

Where $\Delta P$ is meniscus pressure value, $\sigma$ is surface tension, $\theta$ is contact angle of water and set cement, $r_{0}$ is radius of pore.
It could be known from the above formula that the critical radius $r_{0}$ decreased and meniscus pressure value $\Delta P$ of pores increased when the relative humidity of internal of concrete decreased. And the cement paste began to shrinkage that caused by meniscus pressure which acted on the tube wall of pores, and then the pressure stress emerged. In the meantime, the hydration speed of silica fume was faster than cement, which make concrete contain a lot of non-hydration cement particle. And by the addition of silica fume, meniscus pressure of pores in concrete increased, the small straticulate defect between cement particles and cement paste was formed. Even though these defects have less effect on strength of concrete, however, small space around cement particles had vital influence on tensile creep of concrete. When external tension action was applied on, stress of defect parts would be increased, and micro-cracks were appeared around unhydrated cement particles [10].Therefore, it could be seen from mechanism of micro-crack that mixing of silica fume would increase tensile creep of concrete, and the tensile creep would increase gradually with the content of silica fume growth.

\section{CONCLUSION}

(1) Splitting tensile strength and tensile elasticity tension modulus of concrete at age of 3 days increased gradually with the increasing of silica fume content

(2) Autogenous shrinkage of concrete in $1 \mathrm{~d} \sim 10 \mathrm{~d}$ increased gradually with the content of silica fume growth.

(3) The development characteristic of tensile basic creep of concrete with different silica fume content was that development rate was relatively fast after loading $12 \mathrm{~h}$, and slowed down gradually after loading $12 \mathrm{~h}$.

(4) Tensile creep of concrete increased along with the incorporation of silica fume, and it increased gradually with the content of silica fume growth, but the basic law of tensile basic creep development of concrete was not changed.

\section{CONFLICT OF INTEREST}

The authors confirm that this article content has no conflict of interest.

\section{ACKNOWLEDGEMENTS}

This project was supported by Changzhou University, China (No. ZMF1002122), and by the Funds of the Department of science and technology of Jiangsu, China (No. BY2014037-30). The authors would like to thank Mr. Wu Shengxing for his technical contribution.

\section{REFERENCES}

[1] X. Hang, "Pavement Performance of Road Concrete Mixed with Silicon Fume," Concrete, no. 9, pp. 41-44, 2006. (in Chinese)

[2] Y. Yang, "Experimental study on the performance of anti-scouring and wearable concrete with fly ash and slum", Design of Hydroelectric Power Station, vol. 24, no. 3, pp. 64-65, 68, 2008. (in Chinese)

[3] H. Ba, "Mechanism and Assessment Methods of Early age Cracking for High Performance Concrete," Doctoral thesis, Harbin Institute of Technology, Harbin, Chinese, 2003. (in Chinese) 
[4] A. A. Salah, and A. L. David, "Creep, shrinkage and cracking of restrained concrete at early age", ACI Materials Journal, vol. 98, no. 4, pp. 323-331, 2001.

[5] L. Ma, "Exploration of several problems about creep of modern concrete", master thesis, School of Civil Engineer Hohai University, 2006. (in Chinese)

[6] GB/T 50081-2002, Standard for Test Method of Mechanical Properties on Ordinary Concrete. China Architecture \& Building Press, Beijing, China, 2003. (in Chinese)

[7] P. Yang, and Z. Peng, "Discussion the Application of Silica Fume to Concrete," Concrete, no. 1, pp. 11-14, 2002. (in Chinese)
[8] C. Chen, Q. Tu, and Y. Ling, "The Basic Properties and Engineering Applications of Silica Fume Concrete", New Building Materials, no. 4, pp. 43-47, 2008. (in Chinese)

[9] J.C. David, "Some aspects of the mechanism of tensile creep in concrete", ACI Journal Proceedings, vol. 69, no. 10, pp. 645-649, 1972.

[10] S. Igarashi, and M. Kawamura, "Effect of microstructure on restrained autogenous shrinkage behavior in high strength concrete at early age," Materials and Structures, vol. 35 , no. 246 pp. 80-84, 2002.

Received: February 03, 2015

Revised: April 03, 2015

Accepted: May 25, 2015

(C) Xinjie et al.; Licensee Bentham Open.

This is an open access article licensed under the terms of the (https://creativecommons.org/licenses/by/4.0/legalcode), which permits unrestricted, noncommercial use, distribution and reproduction in any medium, provided the work is properly cited. 